\title{
Filtered Containment Venting: Reasons, Technology, Impact on Environment
}

\author{
Jens Beck and Marina Welker \\ AREVA GmbH, Erlangen 91058, Germany
}

Received: July 12, 2016 / Accepted: July 27, 2016 / Published: December 31, 2016.

\begin{abstract}
The AREVA FCVS (filtered containment venting system) is a product family that minimizes the environmental impact in case of a severe accident in a nuclear power plant. It is based on a large-scale test and qualification program as well as on the design, licensing and installation of more than 80 projects worldwide. The product family provides flexibility regarding adaptation to accident scenarios, applicable codes and standards, seismic design, supply chain, implementation and localization. AREVA has broad experience in managing fleet supplies, successful licensing support and cooperation with original equipment manufacturers of pressurized and boiling water reactors.
\end{abstract}

Key words: Filtered containment venting, severe accident mitigation, FCVS.

\section{Introduction}

An external event can cause the loss of all onside power, which can result in a severe accident scenario as emergency core cooling cannot be maintained. This may result in containment over pressurization. A consequence may be the widespread release of highly radioactive fission products. The severe accident in Fukushima on March 11, 2011 demonstrated that this risk is real.

As a response, programs were launched throughout the nuclear industry to figure out the best way to minimize the risk of fission product release to the environment while maintaining containment integrity at the same time. The first approach is to install overpressure protection features which allow the release of the containment atmosphere to the environment. Such installations have to withstand external events and should be equipped with filters to prevent contamination of the environment. The installation of such filtered containment venting systems was one of the worldwide reactions to the

Corresponding author: Dr.-Ing. Jens Beck, section manager for Waste and Isoptopes at the AREVA GmbH Erlangen. events in Fukushima.

In the US, the first approach was also to install venting in BWR (boiling water reactors) at Mark I and Mark II (BWR), as laid down in Ref. [1]. However, the US NRC (National Regulatory Commission) was convinced that the implementation of the FLEX (diverse and flexible coping strategies) [2, 4] concept, which is the establishment of a national response center with sets of backup diesel generators, diesel-driven pumps, etc., would enable core cooling to be maintained in a severe accident. In this way, core melt would be prevented and the containment would not be pressurized beyond the design limit.

However, other countries are pursuing a combined approach implementing additional preventive (e.g., according to the FLEX concept) and mitigation measures (e.g., FCVS (filtered containment venting systems), PAR (passive autocatalytic recombiners)) in order to cope with a postulated severe accident.

The IAEA (International Atomic Energy Agency) ranks events according to the severity of their consequences for the environment according to the INES (International Nuclear Event Scale) [3]. Altogether, there are seven event levels: 
- Anomaly;

- Incident;

- Serious incident;

- Accident with local consequences;

- Accident with wider consequences;

- Serious accident;

- Major accident.

The first three, also called incidents, only have an effect inside a plant, while the four levels of accidents (levels 4-7) involve various levels of radioactive releases to the environment. Three Mile Island, for instance, is ranked level 5 on this scale whereas the severe accidents of Chernobyl and Fukushima are ranked level 7. While the US approach focuses on core cooling and preventing core melt $[2,4,5]$ the IAEA approach generally postulates the release of contaminants $[6,8,9]$. To minimize the probability of radioactive release to the environment measures, such as provided by FLEX, are implemented. If, however, a release of contaminants irrespectively of countermeasures has to be considered, additional measures have to be available to protect the plant personnel and the public. Therefore, all utilities have implemented preventive concepts in order to reduce the core melt probability. In addition, most international utilities are installing additional mitigative measures and systems such as FCVS.

The first AREVA FCVS (FCVS Standard) was developed by AREVA almost 30 years ago in response to the Chernobyl accident.

Over the years, authorities and also utilities have increased the requirements on retention rates, especially regarding organic iodine. As a consequence, AREVA has continuously developed the FCVS Product Family in order to meet a broader variety of challenging performance expectations.

\section{AREVA's Approach}

AREVA's approach towards an almost all-retaining-filter system capable of operation after beyond design basis events reflects the experience made in the last 30 years and takes into account an increasingly demanding safety culture. The gain is that a flexible solution has been developed which can be adapted to a large range of technical and regulatory requirements.

AREVA's FCVS consists of the following stages (see Fig. 1):
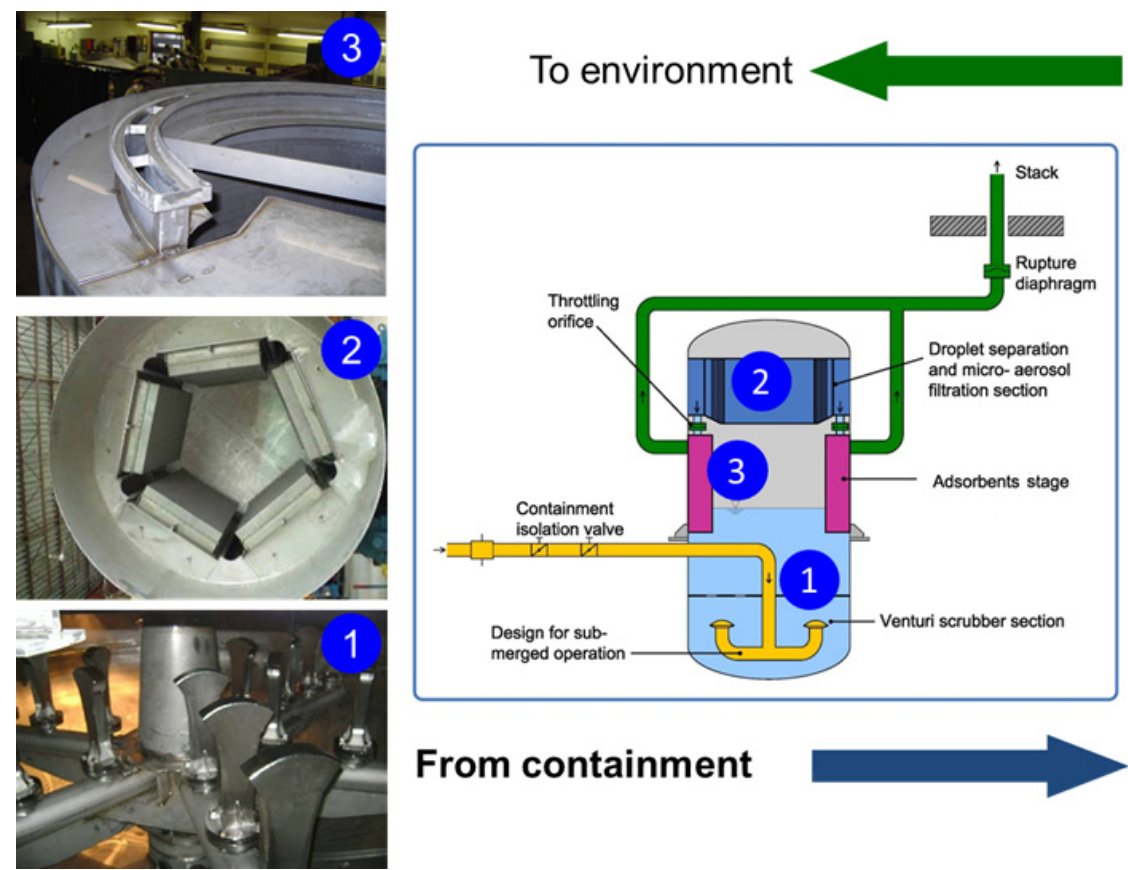

From containment
(3) Molecular sieve section

(2) Metal fiber filter

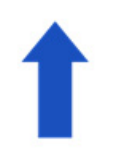

(1) Venturi scrubber

Fig. 1 AREVA's FCVS concept. 


\section{Stage 1: Venturi Scrubber (wet stage)}

The vented gas enters the venturi scrubber vessel and is conducted to a set of venturi nozzles, submerged in a scrubbing liquid. The vented gas is accelerated inside the venturi nozzles to high velocities. The increased dynamic pressure of the vented gas causes its static pressure to decrease, and the high velocity difference provides the passive suction of the surrounding scrubbing liquid. At this stage most aerosols of the vented gas are retained as well as most elemental iodine and large quantities of iodine compounds.

\section{Stage 2: Metal Fiber Filter (dry stage)}

The metal fiber filter retains the droplets and micro-aerosols contained in the vented gas flow downstream of the venturi nozzles. Furthermore, the metal fiber elements capture re-suspended aerosols.

\section{Stage 3: Molecular Sieve Section (dry stage)}

In the molecular sieve section, the gaseous organic iodine contained in the gas flow is retained by adsorption on molecular sieve sorbents in superheated vented gas conditions. High retention rates are achieved as the organic iodine reacts favourably with the molecular sieve absorbent material at high temperatures. In this stage the remaining, re-volatilized elemental and organic iodine is captured.

The different stages can be a standalone (stage 1) or in combination (see Table 1). The AREVA FCVS basic version consists of stage 1 with a demister. Usually, the enhanced FCVS standard version is supplied, consisting of stages 1 and 2. The AREVA FCVS Plus consists of all three stages. The concept is customizable. The third stage version can also be retrofitted later if higher iodine retention rates are needed (I-Catch).

The combination of the above-named three stages allows a modular design to meet the constraints regarding technical requirements and possible locations/compartments in terms of the installation of the system as well as economic constraints.

In addition, the AREVA technology features the following unique advantages:

- Significant reduction of clogging in the dry stage due to the upstream wet scrubber since most of the radioactive aerosols are trapped in the wet stage.

- Reliable retention and avoidance of activity re-suspension in the wet stage: the combination of scrubber with efficient downstream droplet separation provides a very beneficial dry gas condition for the downstream metal fiber fine aerosol filtration stage. This design avoids wet operation of the metal fiber filter sections and facilitates reliable operation. The dry stage significantly reduces possible aerosol and iodine re-volatilization/re-suspension effects.

- High thermal inertia of the wet stage: the trapped radioactive isotopes generate heat.

- $\quad$ In the wet stage $>99 \%$ of the isotopes are trapped in the scrubber. The heat is safely absorbed by the scrubber liquid. The volume of the liquid is sufficient to allow full passive cooling and temperature control by evaporation. The heat transferred from the FCVS to the room where it is installed is significantly reduced. This is important as in SBO (station black-out) scenarios HVAC (heating, ventilation and air-conditioning) is assumed to be out of operation.

- $\quad$ The remaining $<1 \%$ of the isotopes are trapped in the second stage. Due to the low amount of such isotopes in the dry stage the risk of reaching self-ignition temperature at hot spots inside this stage as well as the risk of aerosol melting is significantly reduced.

- Full-scale test and qualification program, to fulfill state-of-the-art international qualification standards even under severe accident conditions including tests with accident typical aerosols, Cs, I, hard-to-retain micro-aerosols [10] as well as tests concerning re-entrainment effects in the course of the US ACE (advanced containment experiments) Filter Test Program [11]. 
Table 1 Combination of different FCVS stages.

\begin{tabular}{|c|c|c|c|c|}
\hline & FCVS Plus & FCVS Standard & FCVS Basic & I-Catch \\
\hline Filtration stages & $\begin{array}{l}\text { 1. High-velocity venturi } \\
\text { scrubber } \\
\text { 2. Meta; fiber filter } \\
\text { 3. Molecular sieve } \\
\text { (I-Catch) }\end{array}$ & $\begin{array}{l}\text { 1. High-velocity venturi } \\
\text { scrubber } \\
\text { 2. Metal fiber filter }\end{array}$ & $\begin{array}{l}\text { 1. High-velocity venturi } \\
\text { scrubber } \\
\text { 2. Demister }\end{array}$ & $\begin{array}{l}\text { 1. N/A } \\
\text { 2. N/A } \\
\text { 3. Passive superheating } \\
\text { and molecular sieve stage } \\
\text { (I-Catch process) } \\
\end{array}$ \\
\hline \multicolumn{5}{|c|}{ Decontamination factors (DF) } \\
\hline Fine aerosols & $>10,000(>99.99 \%)$ & $>10,000(>99.99 \%)$ & $>100(>99 \%)$ & \\
\hline Large aerosols & $>100,000(>99.9999 \%)$ & $>100,000(>99.9999 \%)$ & $>1000(>99.9 \%)$ & \\
\hline Elemental iodine & $>1000(>99.9 \%)$ & $>200(>99.5 \%)$ & $>200(>99.5 \%)$ & \\
\hline Organic iodine & $>10-1000(>90-99.9 \%)$ & $\sim 5(\sim 80 \%)$ & $\sim 5(\sim 80 \%)$ & $>10-1000(>90-99.9 \%)$ \\
\hline
\end{tabular}

- AREVA verified the aerosol and iodine retention for the whole range of the relevant pressures of 0.2-10.0 bar tested at the JAVA Test Facility in Karlstein, Germany [9].

\section{Environmental Impact}

Up to now all severe accidents in nuclear power plants had their cause in unexpected beyond design basis events with release of radioactivity to the environment. In plants equipped with a containment, a defined release of containment pressure would have helped to minimize the impact on the environment.

With a decontamination factor of 2,000 of a filtering system, a dose rate of $4 \mathrm{~Sv}$ (400 rem) would be reduced to $2 \mathrm{mSv}$ (200 mrem) which would significantly decrease requirements for public protection measures or evacuation in the long term. The intention to use filtered containment venting is to reduce radioactive releases to the environment in order to downgrade a potential INES level 7 severe accident scenario (see Fig. 2 [7]) to a level 3 incident.

\section{Conclusions}

AREVA's FCVS Product Family fulfills a broad variety of regulatory requirements, technical specifications and commercial boundary conditions in order to meet customers' needs. For almost 30 years, AREVA has been providing FCVS solutions capable of significant reductions in the release of fission products while meeting different requirements, supply conditions and partnership models.

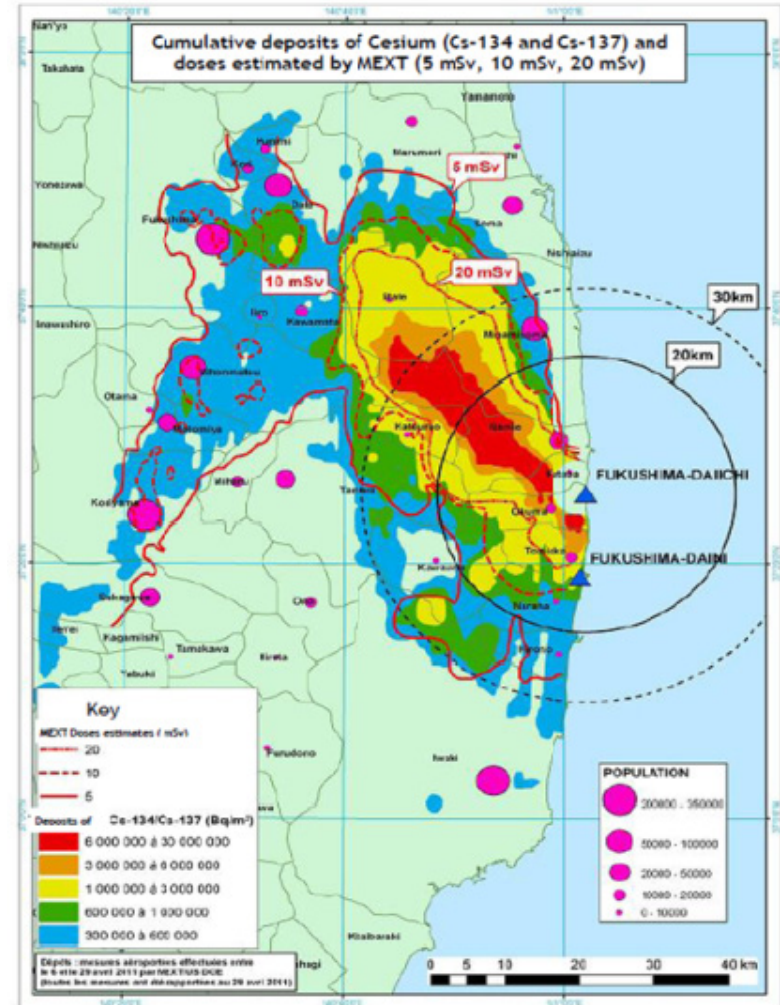

Fig. 2 Permanent evacuation zone.

\section{References}

[1] US NRC. 2013. Issuance of Order to Modify Licenses with Regard to Reliable Hardened Containment Vents Capable of Operation under Severe Accident Conditions. Order EA 13-109. Washington.

[2] BWROG Fukushima Response Committee. 2013. Plant Evaluation of Severe Accident Mitigation Strategies. Revision 1, BWROG-TP-13-001. Accessed December 02, 2016. http://pbadupws.nrc.gov/docs/ML1302/ML13022 A437.pdf.

[3] IAEA. Accessed December 02, 2016. http://www-ns.iaea. org/tech-areas/emergency/ines.asp\#1. 
[4] Nuclear Energy Institute. 2012. Diverse and Flexible Coping Strategies (FLEX) Implementation Guide. NEI 12-06. Washington.

[5] Nuclear Energy Institute Nuclear Notes. 2015. NRC Vote Eliminates Need for External Containment Filters. Washington. Accessed August 21, 2015. http://neinuclearnotes.blogspot.de/2015/08/nrc-vote-elimi nates-need-for-external.html.

[6] IAEA. 2014. The Use of the International Nuclear and Radiological Event Scale (INES) for Event Communication: Guidelines and Good Practices for Setting Up a National Framework on the Effective Use of INES for Event Communication. Vienna.

[7] Institut de Radioprotectionet de Sûreté Nucleaire (IRSN) Report DRPH/2011-10.

[8] NEA/CSNI/R(2014)7. OECD/NEA/CSNI Status Report on Filtered Containment Venting. https://www.oecd-nea. org/nsd/docs/2014/csni-r2014-7.pdf.

[9] The European PASSAM Project on Severe Accident Source Term Mitigation. Accessed December 02, 2016. https://gforge.irsn.fr/gf/project/passam/.

[10] Eckhardt, B., and Losch, N. 2012. "Filtered Containment Venting System Designs. Development, Features, Qualification, Applications." NRC Meeting on Containment Venting Systems. Accessed December 02, 2016. http://pbadupws.nrc.gov/docs/ML1220/ML12206 A263.pdf.

[11] Sehgal, B. R., Ritzman, R., Merilo, M., Rahn, F., and Machiels, A. 1992. "The Advanced Containment Experiments *ACE Project." Transactions of the American Nuclear Society 65. Conference: 8. Pacific Basin Nuclear Conference, Taipei (China). Report number: CONF-920414, Journal ID: ISSN 0003-018X; CODEN: TANSAO; TRN: 93-022644. 